\title{
Texture and Planar Anisotropy in Lean Duplex Stainless Steel Sheet
}

\author{
Jun-ichi HAMADA, ${ }^{1 / *}$ Eiichiro ISHIMARU ${ }^{1)}$ and Hirofumi INOUE ${ }^{2)}$ \\ 1) Research \& Development Center, Nippon Steel \& Sumikin Stainless Steel Corporation, 3434 Shimata, Hikari, Yamaguchi, \\ 743-8550 Japan. \\ 2) Department of Materials Science, Graduate School of Engineering, Osaka Prefecture University, Sakai, $599-8531$ Japan.
}

(Received on March 31, 2016; accepted on June 16, 2016)

\begin{abstract}
The comparison of texture and planar anisotropy of the $r$-value between the lean Type $32101(21.2 \% \mathrm{Cr}$ 1.5\% Ni-5.0\%Mn-0.3\%Mo-0.02\%C-0.22\%N) and standard Type 329J4L (25.2\%Cr-6.9\%Ni-0.7\%Mn-3.0\%Mo$0.02 \% \mathrm{C}-0.11 \% \mathrm{~N})$ duplex stainless steel cold-rolled and annealed sheets were examined. Type 32101 had a weaker texture, especially in the $\alpha$ phase, and a lower planar anisotropy of the $r$-value compared with Type 329J4L. These differences were caused by the cold rolling texture because the $\alpha_{\mathrm{bcc}}$ fiber $(<011>/ /$ RD) texture in Type 32101 decreased during cold rolling. It was revealed that during cold rolling, inhomogeneous deformation easily occurred in Type 32101 because this steel contained a higher volume fraction of the $\gamma$ phase harder than the $\alpha$ phase.
\end{abstract}

KEY WORDS: duplex stainless steel; r-value; planar anisotropy; texture; orientation distribution function; Taylor model; cold rolling; annealing; microstructure; recrystallization; hardness.

\section{Introduction}

Duplex stainless steels (DSS) have a two-phase ferrite $(\alpha)$ and austenite $(\gamma)$ microstructure, and high-alloy steels such as Type 329J4L have been widely applied for the construction of chemical plants, vessels, and tanks, because they have good corrosion resistance and strength. ${ }^{1-6)}$ Recently, DSS were mainly classified into four types: hyper, super, standard, and lean type depending on the corrosion-resistant level. ${ }^{5)}$ Low-alloy steels called lean DSS such as inexpensive Type 32101 with a low Ni and Mo content are balanced by having increased $\mathrm{N}$ and Mn contents. Such steels have been developed for application in the field of plate in particular advances. ${ }^{4)}$ Now, about the use of lean DSS, the application of the plate is the main part, but the expansion of application of the cold-rolled sheet is expected in the future. ${ }^{6}$ From the viewpoint of the stress-induced transformation behavior which changes with chemical composition, temperature, and strain rate, some experimental guidelines on lean DSS sheets with mechanical properties suitable for each application have been shown. ${ }^{7-10)}$ When materials are applied to sheet products, sheet formability and anisotropy in addition to strength and elongation are important, and there are few reports about the formability of standard DSS sheets. ${ }^{11-16)}$ According to these findings, it has been reported that high-alloy DSS sheets have a large planar anisotropy and their texture is different from that of single-phase materials, ${ }^{11-16)}$ but studies on the texture and planar anisotropy of the lean DSS sheets are not found.

\footnotetext{
* Corresponding author: E-mail: hamada.junichi.4m8@nssc.nssmc.com DOI: http://dx.doi.org/10.2355/isijinternational.ISIJINT-2016-185
}

In this study, for lean Type 32101 DSS sheets prepared at different cold rolling reductions and annealing temperatures, both the texture and the planar anisotropy of the $r$-value were investigated, and these results were compared with our previous results $^{16)}$ of the standard Type 329J4L. Additionally, the differences in the recrystallization texture and the planar anisotropy of the $r$-value between lean and standard DSS were discussed by the deformation behavior and the texture formation of the $\alpha$ matrix.

\section{Experimental Procedures}

The chemical compositions of lean Type 32101 and standard Type 329J4L DSS hot-rolled and annealed sheets used in this study are given in Table 1. This table shows that Type 32101 contained lower amounts of $\mathrm{Ni}$ and Mo, and higher amounts of $\mathrm{Mn}$ and $\mathrm{N}$ than Type 329J4L. The stable phases at various temperatures for these steels were calculated using Thermo-Calc. (TCFE5) software, and the results are shown in Fig. 1. These calculations suggest that the stable phase of Type 32101 and Type 329J4L is $\alpha+\gamma$ below $1380^{\circ} \mathrm{C}$ and $1320^{\circ} \mathrm{C}$, respectively, and Type 32101 has more $\gamma$ phase than Type 329J4L. Figure 2 shows the microstructures on the longitudinal section at the center before cold rolling. Both materials before cold rolling were

Table 1. Chemical compositions of steels used (mass $\%$ ).

\begin{tabular}{cccccccccc}
\hline Steel & $\mathrm{C}$ & $\mathrm{Si}$ & $\mathrm{Mn}$ & $\mathrm{P}$ & $\mathrm{S}$ & $\mathrm{Ni}$ & $\mathrm{Cr}$ & $\mathrm{Mo}$ & $\mathrm{N}$ \\
\hline Type 32101 & 0.02 & 0.6 & 5.0 & 0.02 & 0.0004 & 1.5 & 21.2 & 0.3 & 0.22 \\
\hline Type 329J4L & 0.02 & 0.5 & 0.7 & 0.02 & 0.0030 & 6.9 & 25.2 & 3.0 & 0.11 \\
\hline
\end{tabular}



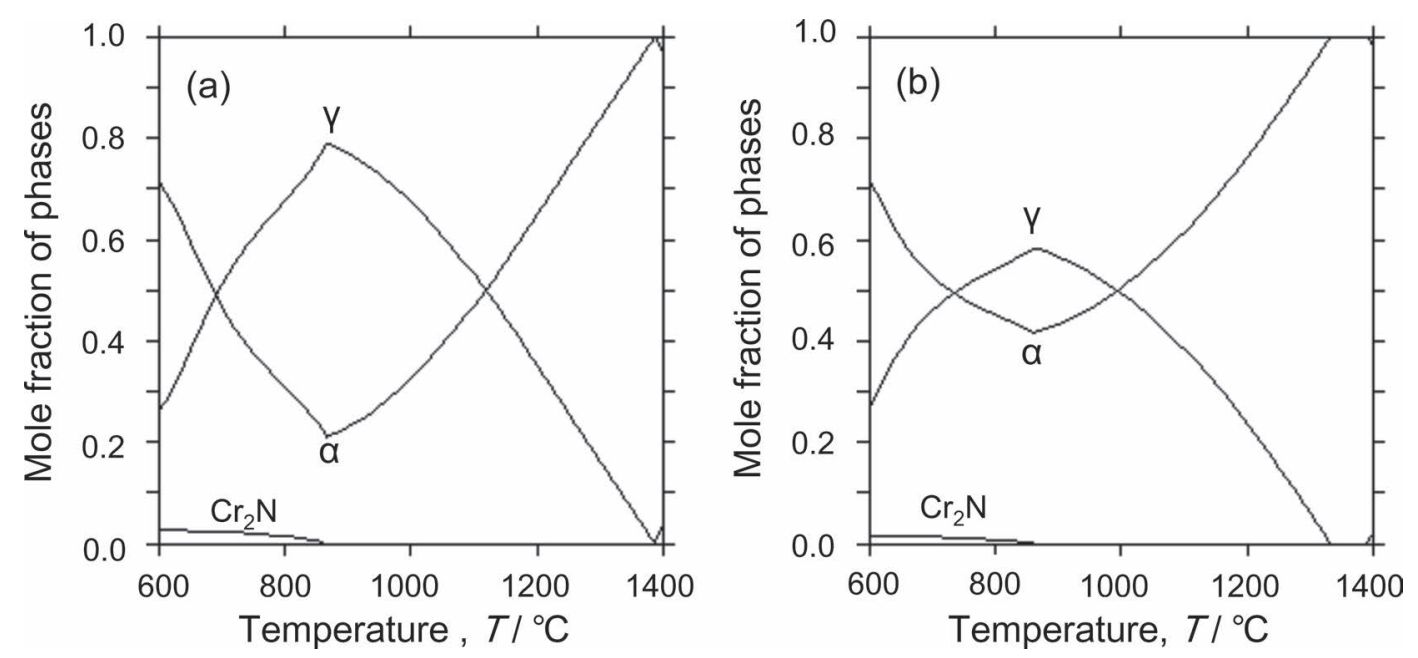

Fig. 1. Calculated equilibrium phase diagram of (a) Type 32101 and (b) Type 329J4L.
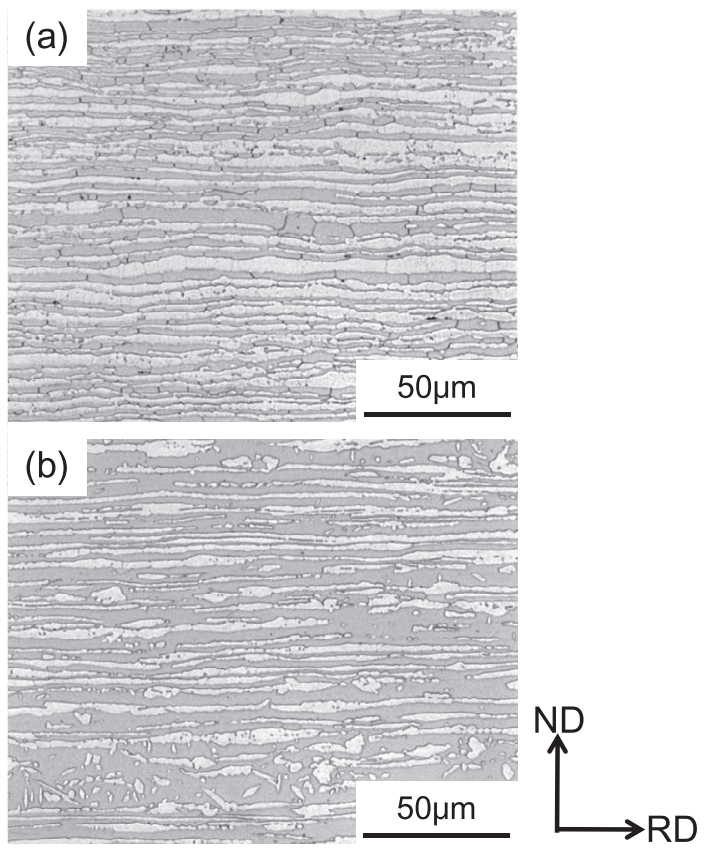

Fig. 2. Optical microstructure of the sheets before cold rolling for (a) Type 32101 and (b) Type 329J4L.

annealed at $1050^{\circ} \mathrm{C}$, and the amount of the $\gamma$ phase of Type 32101 and Type $329 \mathrm{~J} 4 \mathrm{~L}$ were $58 \%$ and $50 \%$, respectively. According to Fig. 1, the calculated amount of the $\gamma$ phase of Type 32101 and Type $329 \mathrm{~J} 4 \mathrm{~L}$ at $1050{ }^{\circ} \mathrm{C}$ were $60 \%$ and $45 \%$, respectively. Thus, although absolute value between calculation and experiment is slightly different, the both results show that Type 32101 has more $\gamma$ phase than Type 329J4L. The thickness $(t)$ of both samples was $4.5 \mathrm{~mm}$. These annealed specimens were cold rolled to $67 \%, 78 \%$, and $89 \%$ reductions in thickness on a laboratory rolling mill, and then the cold-rolled sheets were annealed for $30 \mathrm{~s}$ at $1050,1100,1150$, and $1200^{\circ} \mathrm{C}$, followed by air cooling. The $r$-values of JIS 13B test pieces cut from the finally annealed sheets were measured after $10 \%$ tensile deformation at angles of $0^{\circ}, 45^{\circ}$, and $90^{\circ}$ with respect to the rolling direction. The average $r$-value $\left(r_{\mathrm{m}}\right)$ was calculated using the following equation.

$$
r_{m}=\left(r_{0}+2 r_{45}+r_{90}\right) / 4
$$

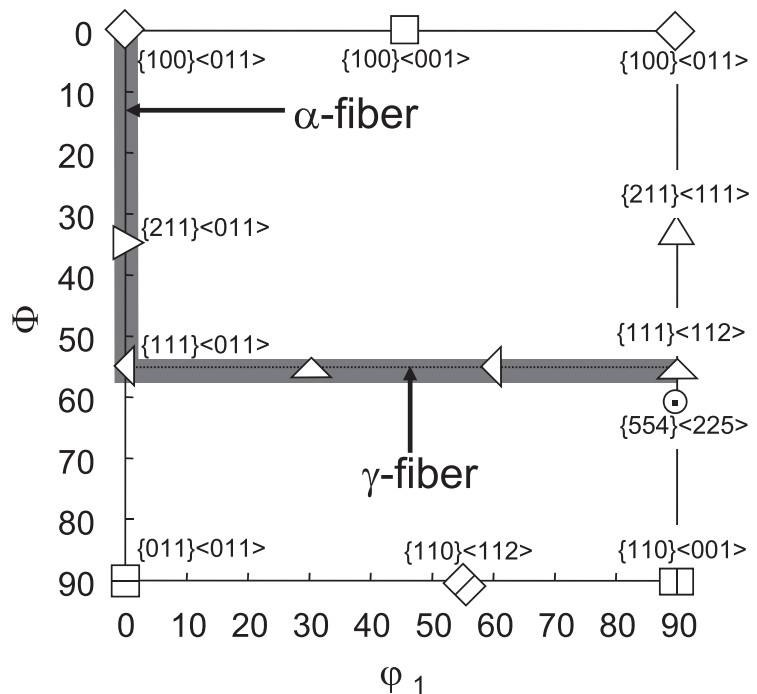

Fig. 3. Some important fiber textures and orientations in Euler space $\left(\varphi_{2}=45^{\circ}\right.$ section $)$.

To reveal the recrystallization process, the cold-rolled sheets with $89 \%$ reduction were heated at $700-1000^{\circ} \mathrm{C}$ and were water-cooled. Microstructural observations were carried out by optical microscopy and scanning electron microscopy (SEM) on the longitudinal section at the center of the finally annealed specimens. The textures were quantitatively examined using the orientation distribution function (ODF). Incomplete pole figures of (310), (200), and (211) for the $\alpha$ phase and (220), (200), and (311) for the $\gamma$ phase of the ND-sections at the center layer of the sheets were measured by means of the Schultz reflection method using $\operatorname{MoK} \alpha$ radiation. From these pole figures, the ODF was determined using the iterative series expansion method. ${ }^{17,18)}$ Figure 3 shows the most important texture components in $\varphi_{2}=45^{\circ}$ section of the ODF (Bunge's notation). Electron back scatter diffraction (EBSD) measurements were made at steps of $0.05-1 \mu \mathrm{m}$ on the the longitudinal section at the center layer of the annealed sheets using a field emission scanning microscope operating at $25 \mathrm{KV}$. In addition, the amount of the $\gamma$ phase was measured quantitatively using a ferrite meter. The microhardness was measured with a Vickers hardness meter using a load of $500 \mathrm{~g}$ in the center layer of the sheet. Moreover, using the nanoindentation tests, 
the hardness of the $\alpha$ and $\gamma$ phases in the electropolished samples was evaluated before cold rolling with an indentation load of $1000 \mu \mathrm{N}$.

\section{Results}

\section{1. $R$-values}

Figure 4 shows the effect of cold rolling reduction on the planar anisotropies of the $r$-values measured in Type 32101 and $329 \mathrm{~J} 4 \mathrm{~L}$ sheets annealed at $1050^{\circ} \mathrm{C}$. In the case of the standard Type 329J4L, in either condition of cold rolling reduction, it showed a strong directionality, i.e., a noticeable planar anisotropy with so-called reverse V-type that had the maximum value at the $45^{\circ}$ direction. The improvements of the average $r$-value and the $r$-value in a diagonal direction with the increase of cold rolling reduction were shown in Type 329J4L. ${ }^{16)}$ On the other hand, in Type 32101, the $r$-values at the $0^{\circ}$ and $90^{\circ}$ directions were much higher, and the $r$-value at the $45^{\circ}$ direction was lower than that in Type 329J4L. Thus, Type 32101 had extremely smaller

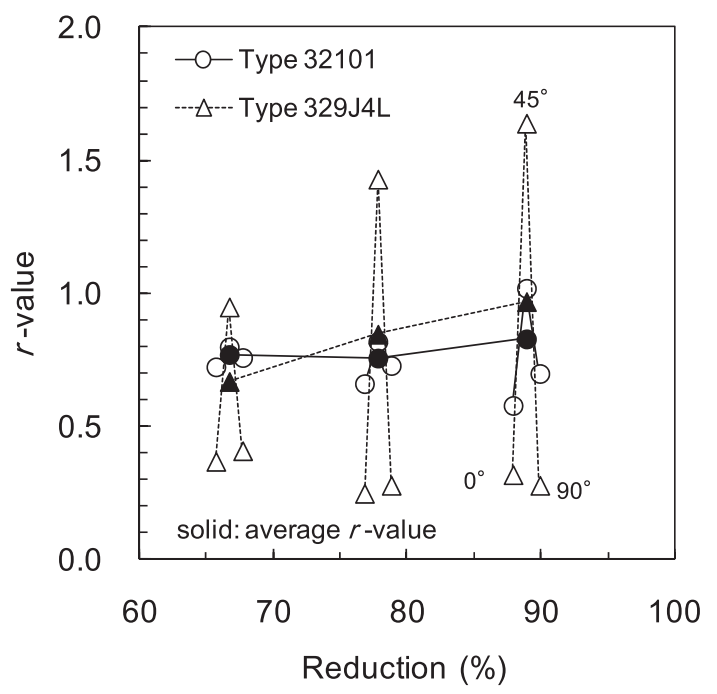

Fig. 4. Effect of cold rolling reductions on planar anisotropy of $r$-value for sheets annealed at $1050^{\circ} \mathrm{C}$.

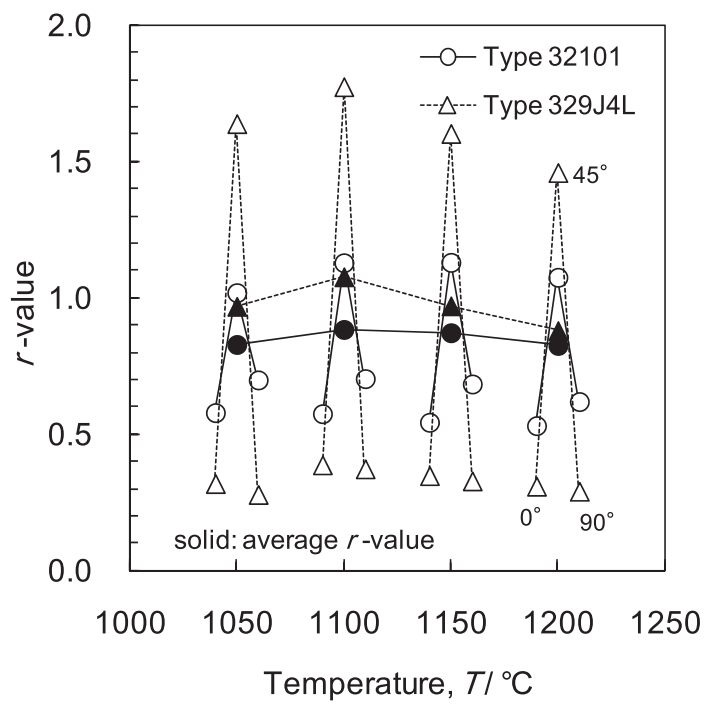

Fig. 5. Effect of annealing temperature after cold-rolling on planar anisotropy of $r$-value for the annealed sheets with $89 \%$ cold rolling reduction. anisotropy in the $r$-value than Type 329J4L, and reduction dependence of the average $r$-value was small.

Figure 5 shows the effect of annealing temperature on the planar anisotropies of the $r$-values measured in Type 32101 and Type 329J4L sheets with $89 \%$ cold rolling reduction. Type 32101 had smaller annealing temperature dependence in the average $r$-value than Type 329J4L. Figure 6 shows changes in the fraction of the $\gamma$ phase with annealing temperature, which were measured using a ferrite meter. The change in the final annealing temperature led to a significant change in the fraction of the $\gamma$ phase, and the fraction of the $\alpha$ phase increased with increasing annealing temperature, as showed in Figs. 1 and 6. Generally, high temperature annealing often improves the $r$-value in ferittic stainless steel sheets, ${ }^{19,20)}$ but the $r$-value in the DSS is different from that in a single $\alpha$ phase. The fraction of $\alpha$ phase increases

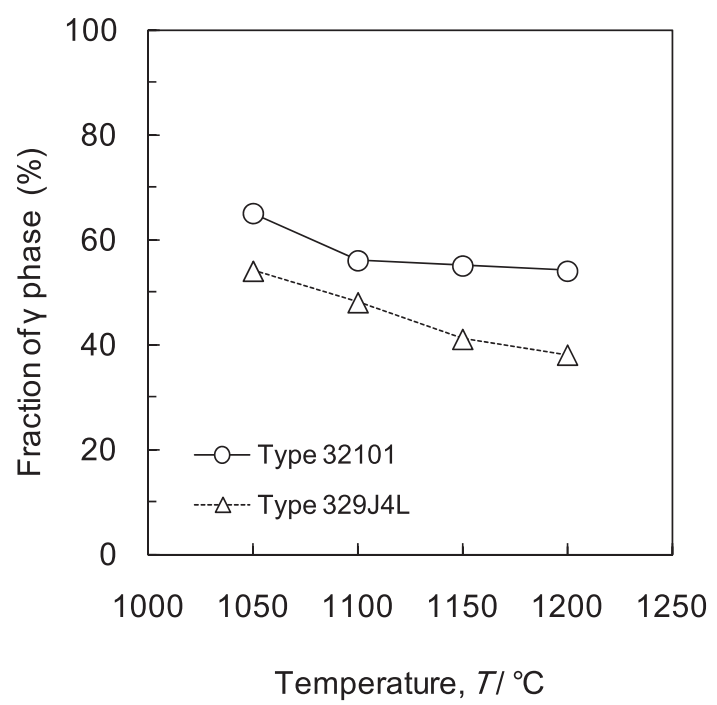

Fig. 6. Effect of annealing temperature on the fraction of the $\gamma$ phase.
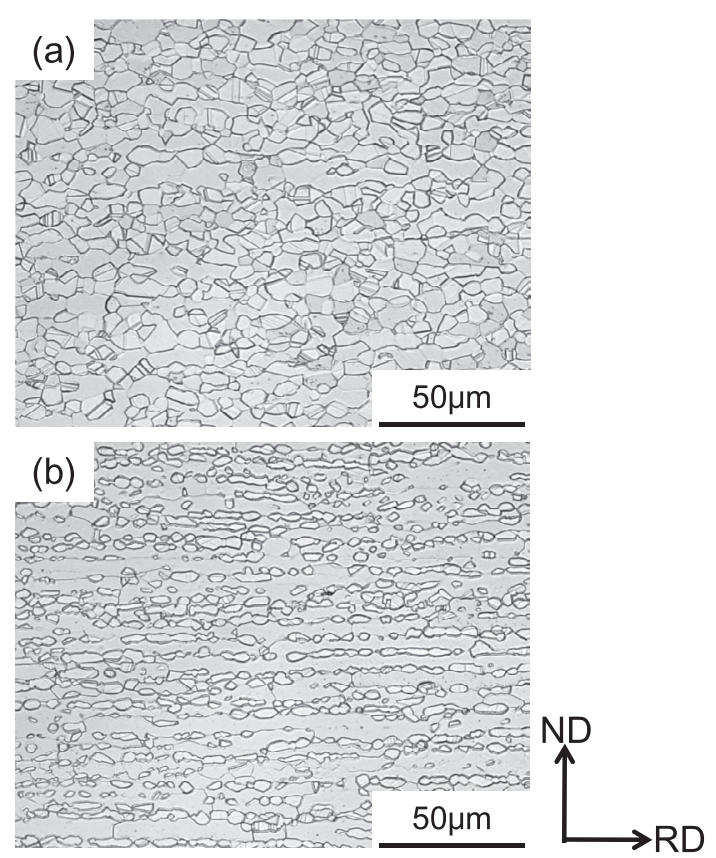

Fig. 7. Optical microstructures of the sheets cold rolled to $78 \%$ reduction and annealed at $1050^{\circ} \mathrm{C}$ for (a) Type 32101 and (b) Type 329J4L. 

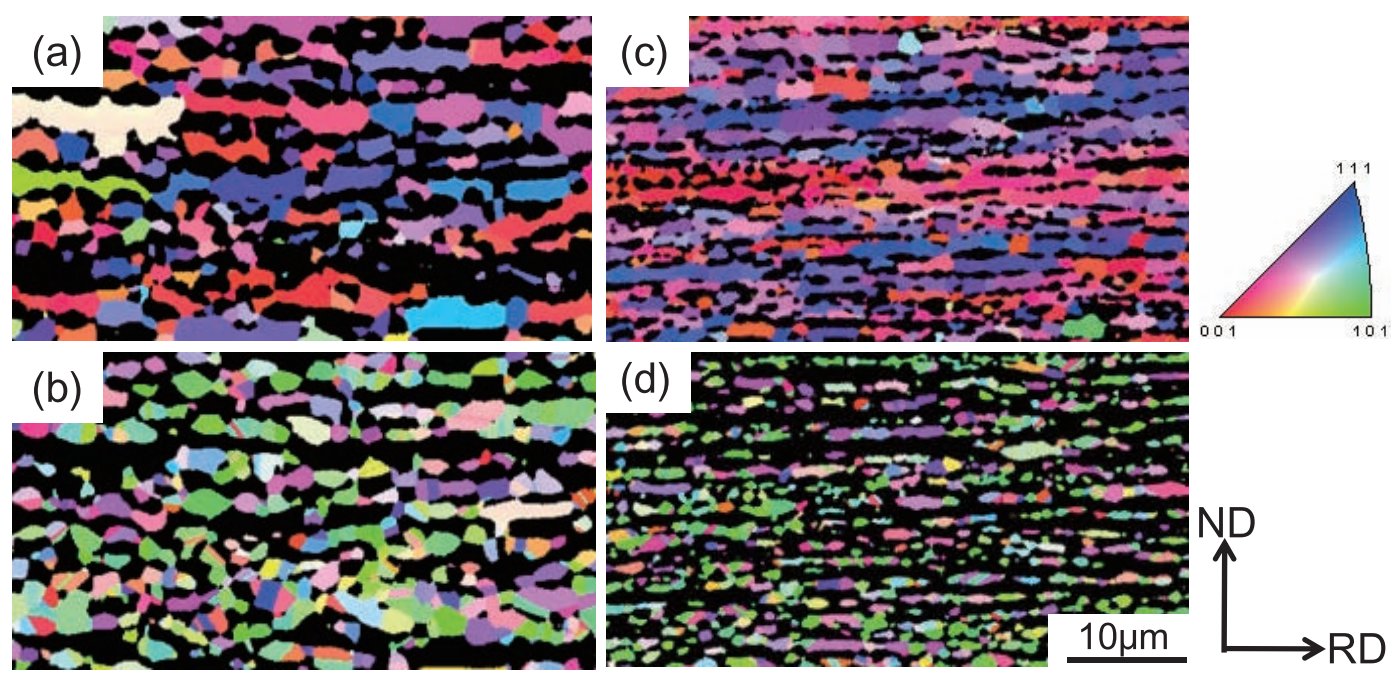

Fig. 8. Inverse pole figure maps of (a), (c) $\alpha$ phase and (b), (d) $\gamma$ phase obtained from sheets cold rolled to $89 \%$ reduction and annealed at $1050^{\circ} \mathrm{C}$ for (a), (b) Type 32101 and (c), (d) Type 329J4L.

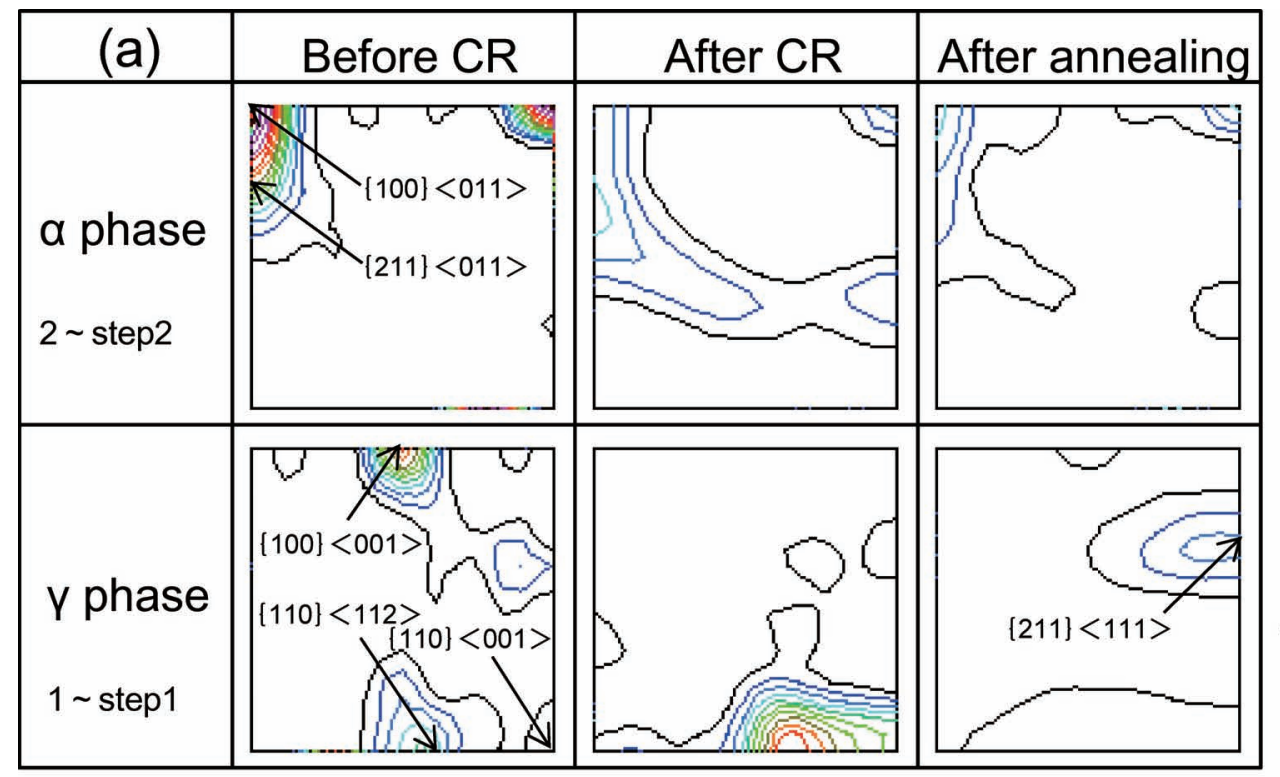

Contour Levels:

$\begin{array}{lllll}2.0 & 4.0 & 6.0 & 8.0 & 10.0\end{array}$

12.014 .016 .018 .020 .0

22.024 .026 .028 .030 .0

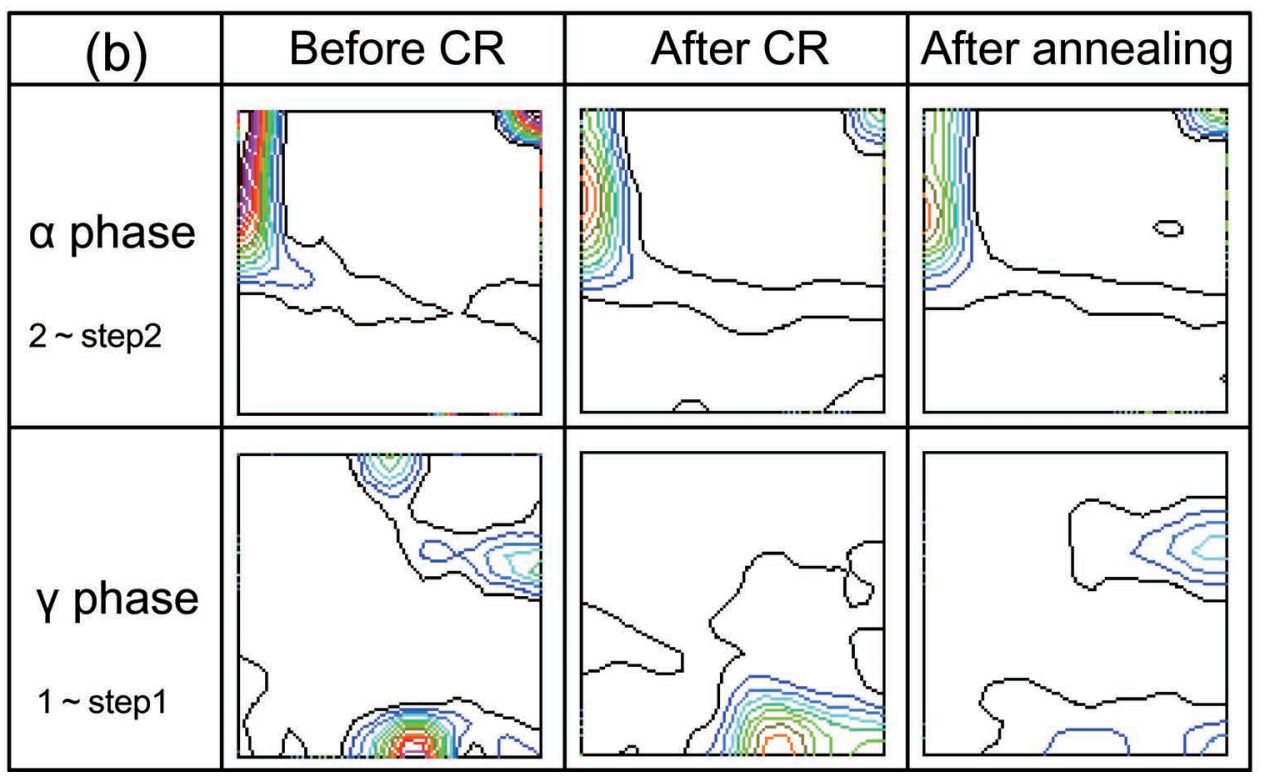

Contour Levels:

$\begin{array}{lllll}2.0 & 4.0 & 6.0 & 8.0 & 10.0\end{array}$

12.014 .016 .018 .020 .0

22.024 .026 .028 .030 .0

Fig. 9. $\varphi_{2}=45^{\circ}$ sections of ODFs in each process of (a) Type 32101 and (b) Type 329J4L cold rolled to $78 \%$ reduction and annealed at $1050^{\circ} \mathrm{C}$. Contour levels: $2-28$ at a step of 2 for $\alpha$ phase, and 1-6 at a step of 1 for $\gamma$ phase. 
with high temperature annealing in the case of DSS. Therefore, it is thought that the increase of $\alpha$ phase influences the temperature dependence in the average $r$-value in view of the fact that the change of the texture of $\alpha$ phase is extremely small as mentioned later. Because Type 32101 has a higher fraction of $\gamma$ phase than Type 329J4L at high temperatures, it is inferred that there is little heat-treatment temperature dependence.

\subsection{Microstructures and Textures}

Figure 7 shows microstructures (TD plane) of the sheets cold rolled to $78 \%$ reduction and annealed at $1050^{\circ} \mathrm{C}$. Figure 8 shows inverse pole figure maps in the longitudinal section of the sheets cold rolled to $89 \%$ and annealed at $1050^{\circ} \mathrm{C}$, obtained by EBSD measurements. In Type 329J4L sheet, the $\alpha$ phase elongated parallel to the rolling direction and the $\gamma$ phase precipitated. Type 32101 had $\alpha+\gamma$ two-phase microstructure, similar to Type 329J4L, but the microstructure had a comparatively equiaxed grains.

Figure 9 shows $\varphi_{2}=45^{\circ}$ sections of ODFs before and after cold rolling with $78 \%$ reduction and after annealing at $1050^{\circ} \mathrm{C}$ in Type 32101 and Type 329J4L sheets. Before cold rolling, namely, in the hot-rolled and annealed sheet, a remarkable difference was not observed in the $\alpha$-phase texture of both steels. The $\alpha$ phase had a strong $\alpha_{\mathrm{bcc}}$-fiber of $<011>/ / \mathrm{RD}(\{100\}<011>-\{111\}<011>)$, especially $\{100\}<011>$, and the $\gamma$ phase had $\{011\}<211>$ (Brass orientation), $\{112\}<111>$ (Copper orientation), $\{100\}<001>$ (Cube orientation), and $\{011\}<100>$ (Goss orientation). These results are consistent with previous studies. ${ }^{15,16)}$ By cold rolling, in both steels, the $\alpha_{\mathrm{bcc}}$-fiber was the main orientation in the $\alpha$ phase, and the $\alpha_{\mathrm{fcc}}-$ fiber $(<110>/ / \mathrm{ND})$ composed of Brass and Goss orientations were main in the $\gamma$ phase. But in Type 32101, the intensity of the $\alpha_{\mathrm{bcc}}$-fiber in the $\alpha$ phase became considerably weaker and changed greatly after cold rolling. After final annealing, the features of a strong $\alpha_{\mathrm{bcc}}$-fiber and an undeveloped $\gamma_{\mathrm{bcc}}-$ fiber in Type 329J4L are consistent with the previous studies. ${ }^{11-16,21,22)}$ On the other hand, although the $\alpha_{\mathrm{bcc}}$-fiber was also the main orientation in Type 32101, its intensity was considerably weaker than Type 329J4L. In the $\gamma$ phase, Copper orientation was the main orientation in both steels, and Brass and Goss orientations were weak in Type 32101. The present study revealed that the cold-rolled and annealed sheet of the lean DSS sheet had a weak $\alpha_{\mathrm{bcc}}$-fiber texture compared with the standard DSS sheet, and it is inferred that this difference is mainly related to a characteristic of the planar anisotropy of the $r$-value. Presumably this difference of the annealing textures results from significantly different cold rolling textures in the $\alpha$ phase.

\section{Discussions}

\subsection{Effect of Texture on Planar Anisotropy}

By this experimental comparison, the lean DSS Type 32101 sheet had a weaker texture and smaller anisotropy of $r$-value than the standard DSS Type 329J4L sheet. To clarify the effect of texture on the anisotropy of $r$-value, the predictive calculations of the planar anisotropies of the $r$-value in polycrystalline materials were conducted using the ODF in conjunction with the Taylor model. ${ }^{23-28)}$ In a pre- vious paper, ${ }^{16)}$ the authors illustrated that the texture of the $\alpha$ phase in Type 329J4L was dominant for the anisotropy of $r$-value. Furthermore, like a case of single-phase ferritic steels, ${ }^{20,29)}$ the $r$-values in Type $329 \mathrm{~J} 4 \mathrm{~L}$ calculated from the texture of the $\alpha$ phase using the relaxed-constraints (RC) model with the RC1323 and a critical resolved shear stress (CRSS) ratio of 1.1 were in good agreement with the experimental values. ${ }^{16)}$ Here, the RC1323 model, i.e., the pancake version in which $e 13$ and $e 23$ (where 1,2, and 3 are defined as the tensile, width, and thickness directions, respectively) were left free, and the CRSS ratio was the same as that for the $\{211\}$ and $\{110\}$ glide planes $\left(\tau_{c\{211\}} / \tau_{c\{110\}}\right)$. Because these materials may have inhomogenious texture along the sheet thickness, we should use the overall texture through sheet thickness for an approximate evaluation. ${ }^{16,20,29)}$ But in this study, for the purpose of a qualitative comparison of anisotropy of $r$-value about these DSS sheets, the predictions of anisotropies of $r$-values by using the RC1323 model with a CRSS ratio of 1.1 were performed from the ODFs of the $\alpha$ phase in the center layer. Figure $\mathbf{1 0}$ shows the planar anisotropies of the measured and calculated $r$-values of the sheets cold rolled to $78 \%$ reduction and annealed at $1050^{\circ} \mathrm{C}$. As for the prediction from the texture of the $\alpha$ phase, Type 32101 had smaller anisotropy in $r$-value than Type $329 \mathrm{~J} 4 \mathrm{~L}$, and the tendency was similar to a previous experiment. From this result, it is concluded that the small anisotropy in $r$-value of the lean DSS Type 32101 sheet was caused by a weaker texture of the $\alpha$ phase compared with the standard DSS Type 329J4L sheet. In addition, because the $r$-value of the $\{100\}<011>$ and $\{211\}<011>$ ideal orientations belonging to the $\alpha_{\mathrm{bcc}}$-fiber showed reverse $\mathrm{V}$-type that had the maximum value at the $45^{\circ}$ direction and low values at the $0^{\circ}$ and $90^{\circ}$ directions, ${ }^{16,20,29)}$ it is estimated that Type 32101 with weaker $\alpha_{\mathrm{bcc}}$-fiber had higher $r$-values at the $0^{\circ}$ and $90^{\circ}$ directions and a lower $r$-value at the $45^{\circ}$

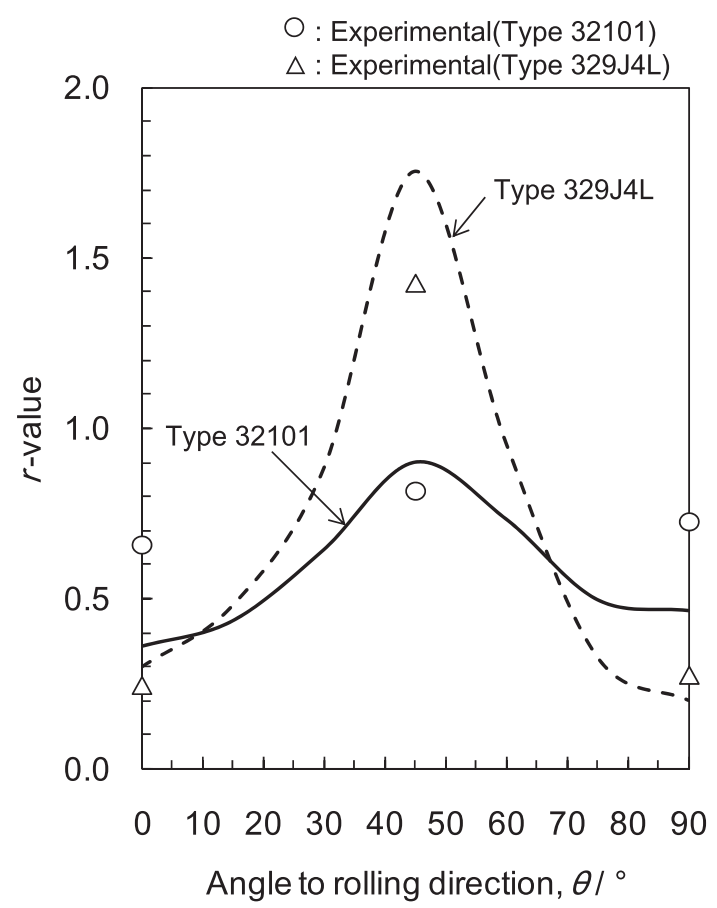

Fig. 10. Planar anisotropy of the $r$-value measured and calculated using $\mathrm{RC} 1323$ model from texture for the sheets cold rolled to $78 \%$ reduction and annealed at $1050^{\circ} \mathrm{C}$. 
direction than Type 329J4L.

\subsection{Texture Formation of Lean DSS Sheet}

In Type 32101, it was recognized that the development of the cold rolling and recrystallization textures were weak in comparison with Type 329J4L, and in conjunction with this, further findings were found from the viewpoint of texture formation in heat treatment and cold rolling. Figure 11 shows the ODFs during heating for the cold-rolled sheets with $89 \%$ reduction. The change of macro-texture during the heat treatment process was extremely small in $\alpha$ phase, and it is estimated that the influence of the $\alpha$ phase cold rolling texture is strong. In the previous investigation of the microstructural evolutions in $(\alpha+\gamma)$ phases DSS caused by thermo-mechanical processing, which combines deformation and heat treatment, no recrystallizaition of the $\alpha$ matrix took place when the initial microstructure before cold rolling was fine. ${ }^{30-32)}$ Moreover, in the standard Type 329J4L DSS sheets, it has been reported that the $\alpha_{\mathrm{bcc}}$-fiber, which was very hard to recrystallize, ${ }^{33,34)}$ remained strong. ${ }^{15,16)}$ Therefore, it was estimated that the reason of a weaker texture of Type 32101 was caused by the cold rolling microstructure.

Figure 12 shows the scanning electron microstructure in the TD section of cold-rolled sheets. By cold rolling, both $\alpha$ and $\gamma$ phases became lamellar structure parallel to the rolling plane, but a visible difference between Type 32101 and $329 \mathrm{~J} 4 \mathrm{~L}$ was in the form of cold rolling microstructure. Thus, the microstructure of Type 32101 exhibited more lenticular bulging than Type 329J4L. For DSS, the observation of local shear bands after cold rolling have been reported. ${ }^{21,22,35,36)}$ Blicharski $^{36)}$ stated that the formation of shear bands in $\alpha$ matrix was induced by the presence of the $\gamma$ phase having a high density of deformation twins. The reason why the microstructure after cold rolling of Type 32101 was more heterogeneous than Type $329 \mathrm{~J} 4 \mathrm{~L}$, is thought to be a high volume fraction of the $\gamma$ phase and a difference in hardness between the $\alpha$ and $\gamma$ phases to be mentioned later.

Figure 13 shows local orientation maps of the $\alpha$ phase

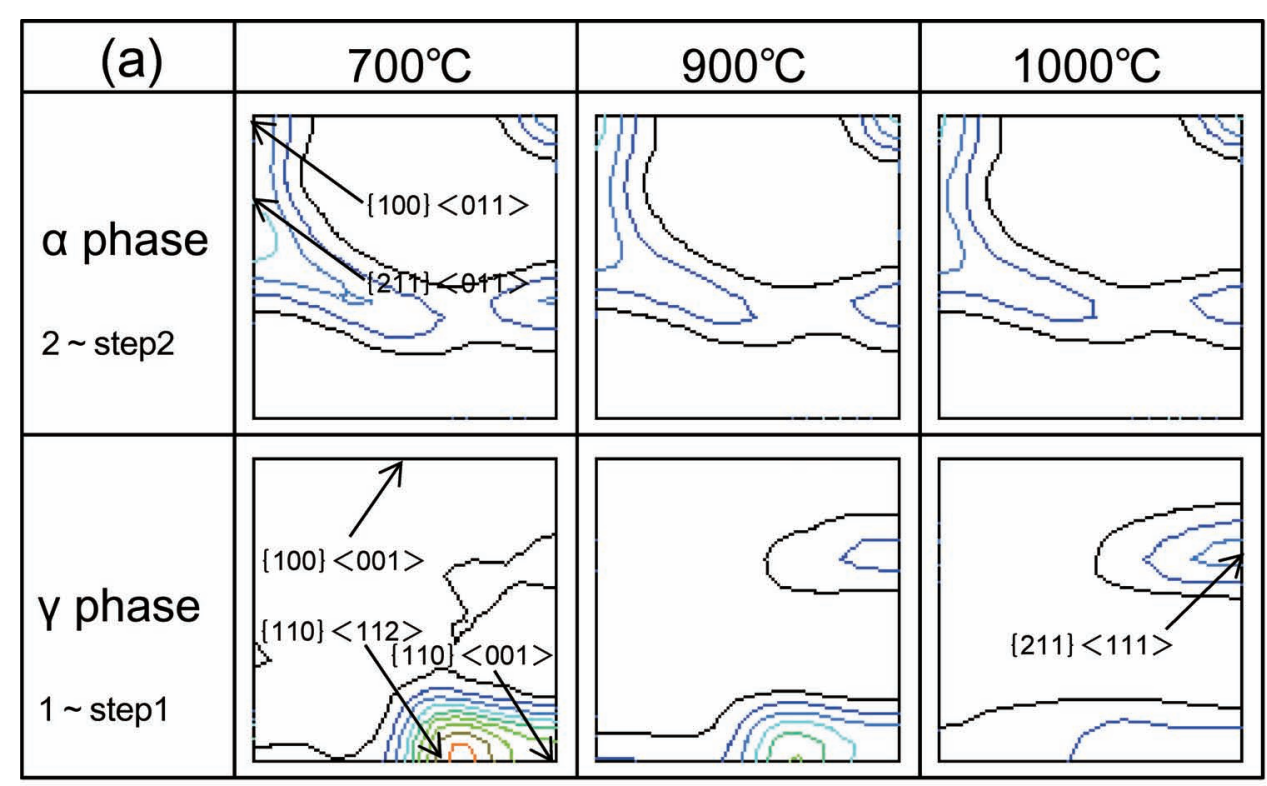

Contour Levels:

$\begin{array}{lllll}2.0 & 4.0 & 6.0 & 8.0 & 10.0\end{array}$

12.014 .016 .018 .020 .0

22.024 .026 .028 .030 .0

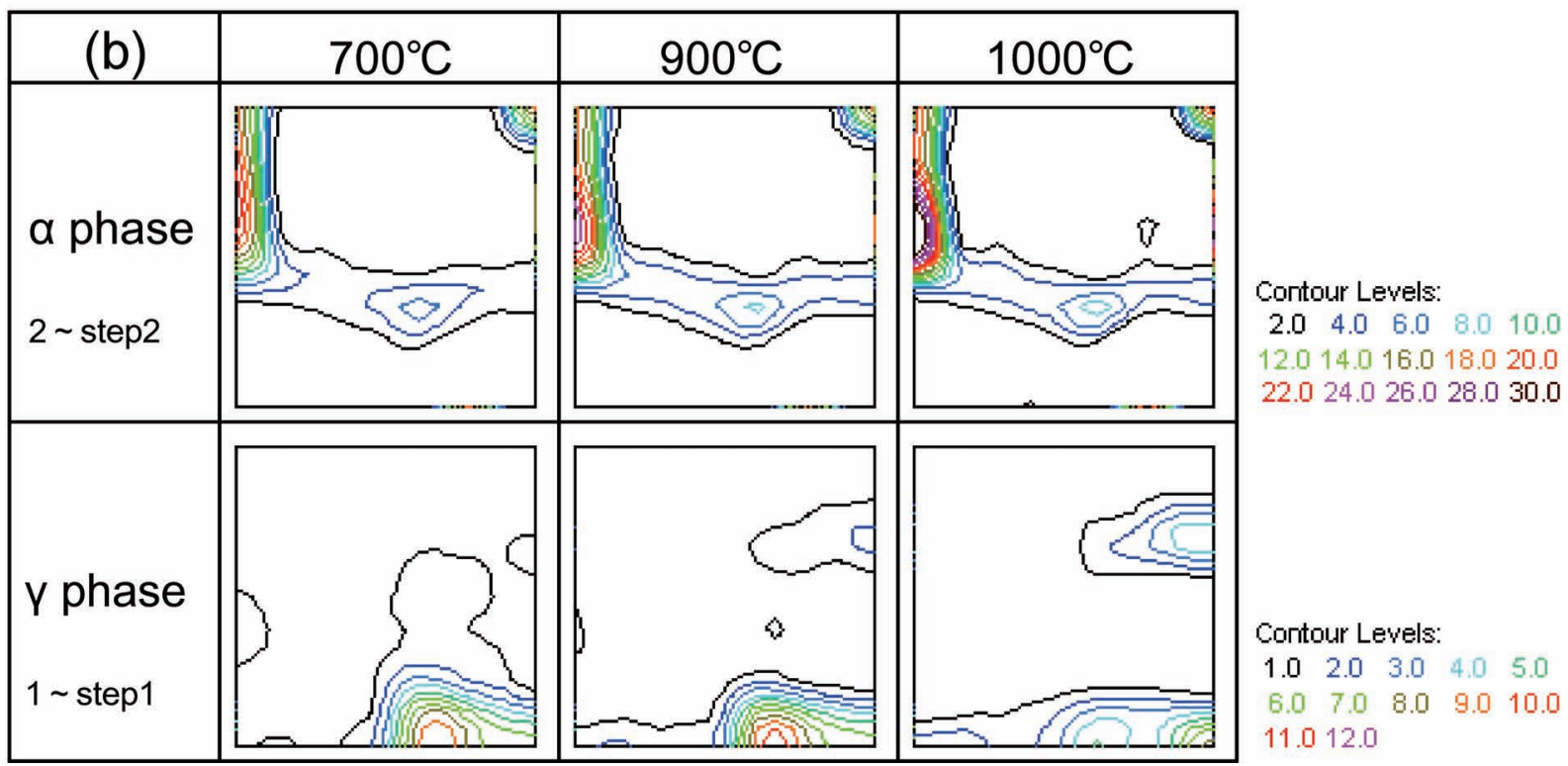

Fig. 11. $\varphi_{2}=45^{\circ}$ sections of ODFs during heating for the cold-rolled sheets of (a) Type 32101 and (b) Type 329J4L cold rolled to $89 \%$ reduction and annealed for $1 \mathrm{sec}$. Contour levels: $2-28$ at a step of 2 for $\alpha$ phase, and 1-6 at a step of 1 for $\gamma$ phase. 
after annealing at $700^{\circ} \mathrm{C}$ for $1 \mathrm{~s}$. The microstructure after annealing of Type 32101 was wavy like a cold-rolled sheet, and a number of oblique lines across the $\alpha$ and $\gamma$ phases were observed as indicated with the white arrows in Figs. 13(a) and 13(c). Fine grains with different orientations from the surrounding were observed as narrow band-like traces in Type 32101. Therefore, they are considered to be recrystallized grains formed in shear bands at the early stage of recrystallization. In contrast, Type 329J4L had few such microstructure. In general, nucleation is associated with
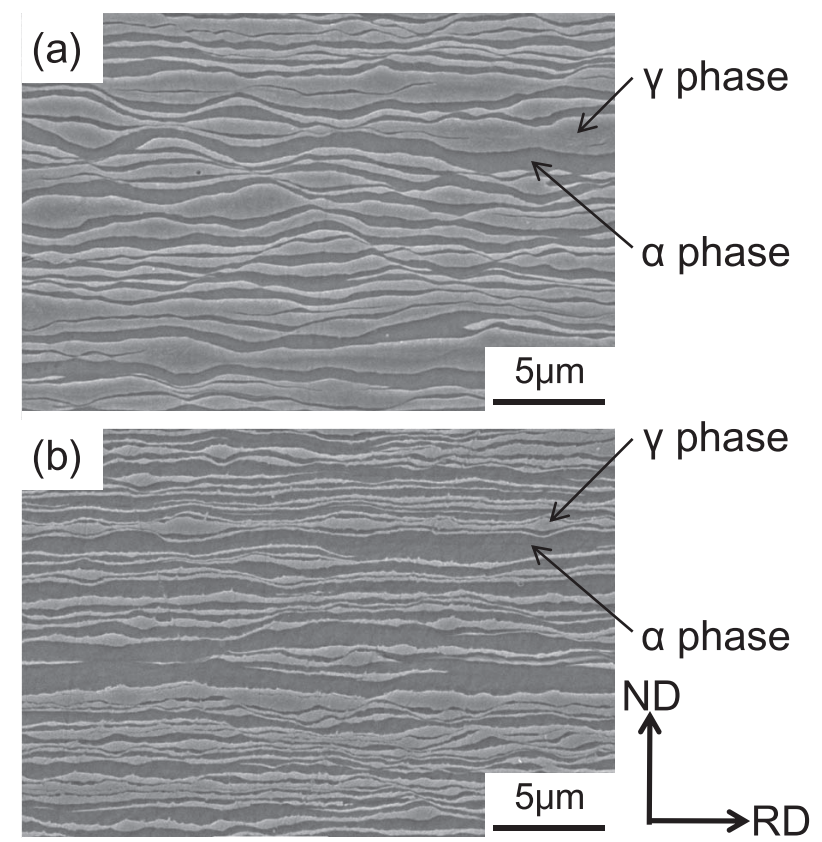

Fig. 12. Scanning electron microstructures of $89 \%$ cold-rolled sheets in (a) Type 32101 and (b) Type 329J4L. inhomogeneous deformed microstructure such as transition bands, shear bands, grain boundaries and the deformation zones around hard particles. ${ }^{37)}$ Blicharski ${ }^{41)}$ showed that the shear band in DSS sheet acted as preferred sites for formation of recrystallization nuclei in the $\alpha$ phase. Because Type 32101 is easy to form more inhomogeneous deformed microstructure than type $329 \mathrm{~J} 4 \mathrm{~L}$, recrystallization is easy to occur. It is likely that this will suppresses the remaining of the $\alpha_{\mathrm{bcc}}$-fiber in the recrystallization process. A similar phenomenon has been reported for cold rolling and recrystallization textures in a Type 430 ferritic stainless steel sheet with $\alpha+\alpha^{\prime}$ microstructure. ${ }^{38-40)}$ These results suggested that the deformation zone forming around the hard $\alpha^{\prime}$ promoted randomization in texture during cold rolling. To understand these results from the calculated equilibrium phase diagram, we considered the possibility that a shear band could be easily formed in Type 32101, which had a higher fraction of the $\gamma$ phase. More detailed observations of inhomogeneous deformed microstructure and recrystallization behavior in the interface between $\alpha$ and $\gamma$ phases will be necessary in future.

One of other factors that give inhomogeneity to the $\alpha$ phase during the cold rolling process may be the difference in hardness between the $\alpha$ and $\gamma$ phases. Figure 14 shows changes in macrohardness in both $\alpha$ and $\gamma$ phases during heat treatment for the $89 \%$ cold-rolled sheets. Type 32101 was harder than Type 329J4L after cold rolling, and consequently was quicker to soften and finally became softer than Type 329J4L after high temperature heat treatment. It is inferred that the fraction of $\gamma$ phase and the $\alpha / \gamma$ phase hardness difference influence a macrohardness difference in the cold-rolled sheets and a recrystallization behavior difference influence the softening behavior difference between Type 32101 and Type 329J4L. Figure 15
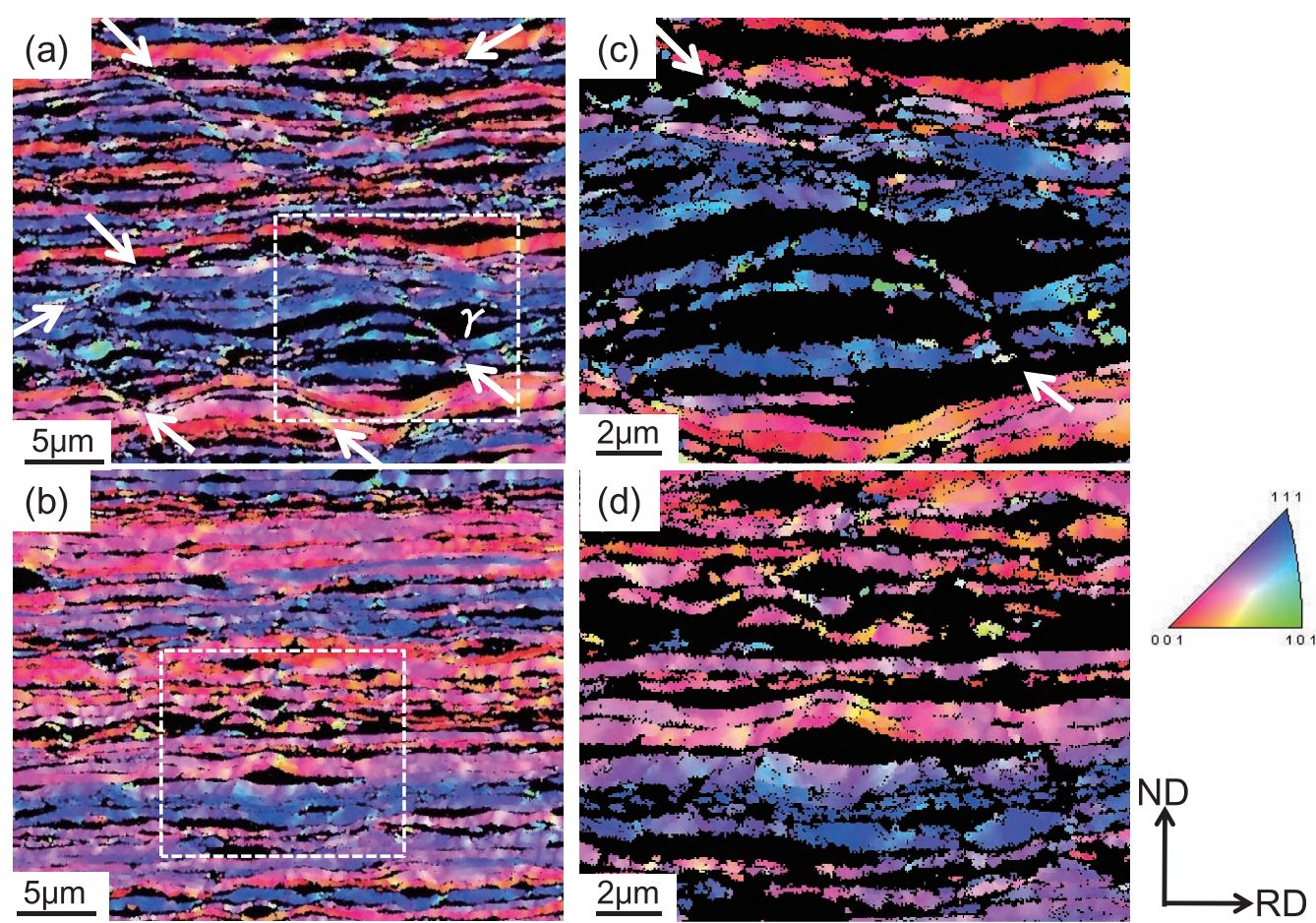

Fig. 13. Local orientation maps of $\alpha$ phase in Type 32101 ((a) and (c)) and Type 329J4L ((b) and (d)), which were annealed at $700^{\circ} \mathrm{C}$ for $1 \mathrm{~s}$. The black part is $\gamma$ phase. (c) and (d) are magnified images of the dashed line in (a) and (b), respectively. 
shows the examples of images of microstructure, load-depth curves, and the nanohardness values for each phase in Type 32101 and Type 329J4L. In Type 329J4L, the nanohardness of both phases was not a remarkable difference in the $\alpha$ and $\gamma$ phases (4.10-4.21 GPa and 3.89-4.14 GPa, respectively). Aramaki et $a l .{ }^{42)}$ reported that the nanohardness of the $\alpha$ and $\gamma$ phases was $3.76 \mathrm{GPa}$ and $3.81 \mathrm{GPa}$, respectively, in the $22.5 \% \mathrm{Cr}-5.4 \% \mathrm{Ni}-3.2 \% \mathrm{Mo}-0.015 \% \mathrm{C}-0.15 \% \mathrm{~N}$ alloy steel after a solid solution treatment at $1070^{\circ} \mathrm{C}$ for $1200 \mathrm{~s}$. Type $329 \mathrm{~J} 4 \mathrm{~L}$ in the present study was harder than their steel, but the hardness of each phase was approximately equal to their results. On the other hand, in Type 32101 of the present study, the value of nanohardness in the $\alpha$ and $\gamma$ phases was measured to be 3.27-3.78 and 4.14-4.68 GPa, respectively. Fang et al. ${ }^{43)}$ reported that the nanohardness of the $\alpha$ and $\gamma$ phases were 4.03 GPa and 5.09 GPa, respectively, in Type 32101 after a solid solution treatment at $1100^{\circ} \mathrm{C}$ for $30 \mathrm{~min}$. Thus, although the values of our examination were lower

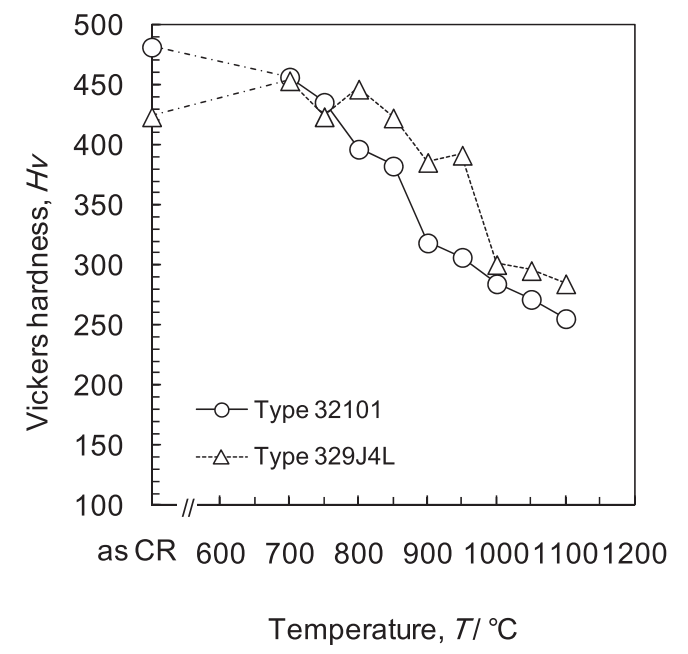

Fig. 14. Changes in Vickers hardness of $89 \%$ cold-rolled and $1 \mathrm{~s}$ annealed sheets.

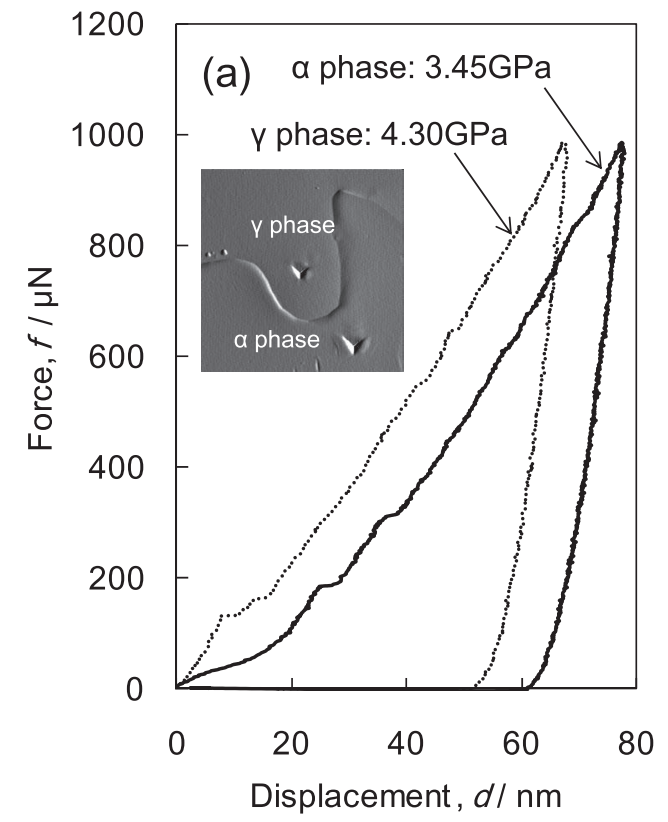

than theirs, the $\gamma$ phase was harder than the $\alpha$ phase in both studies. Table 2 shows the element partitioning at $1050^{\circ} \mathrm{C}$ based on Thermo-Calc. The $\gamma$ phase in Type 32101 contained high N content compared with Type 329J4L. There are some observations of strengthening by various types of interstitial or substitutional elements, and the increase of $\mathrm{N}$ content in solid solution in the $\gamma$ phase leads it to harden effectively. ${ }^{44-47)}$ Although the type of elements and their quantities in solid solution differ between Type 32101 and Type 329J4L, N content may be the reason why the $\gamma$ phase in Type 32101 was harder than the $\alpha$ phase and $\gamma$ phase in Type 329J4L. On the other hand, $\alpha$ phase in Type 329J4L contains a lot of $\mathrm{Ni}$ and Mo, it is guessed that the $\alpha$ phase is harder than that in Type 32101. Therefore, it is thought that the difference in hardness between $\alpha$ phase and $\gamma$ phase are relatively small in Type 329J4L. In addition to the difference in the fraction of the $\gamma$ phase, the hard $\gamma$ phase would result in the formation of the heterogeneous microstructures such as shear bands during cold rolling, and the weakening of the $\alpha_{\mathrm{bcc}}$-fiber texture. As a result, it is thought that the weakening of the recrystallization texture and the small anisotropy of the $r$-value occurred in Type 32101. But a systematic study about the influence of a fraction of the $\alpha / \gamma$ phase and each alloy element on the deformation behavior, recrystallization behavior and formability will be necessary in future.

Table 2. Element partitioning at $1050^{\circ} \mathrm{C}$ in Type 32101 and Type 329J4L by using the Thermo-Calc (mass\%).

\begin{tabular}{cccccccccc}
\hline Steel & Phase & Fe & C & Si & Mn & Ni & Cr & Mo & N \\
\hline $\begin{array}{c}\text { Type } \\
\text { 32101 }\end{array}$ & FCC & 72.008 & 0.032 & 0.569 & 5.279 & 1.757 & 19.774 & 0.244 & 0.337 \\
& BCC & 69.818 & 0.002 & 0.649 & 4.558 & 1.094 & 23.456 & 0.389 & 0.034 \\
\hline $\begin{array}{c}\text { Type } \\
\text { 329J4L }\end{array}$ & FCC & 65.148 & 0.042 & 0.481 & 0.799 & 9.143 & 21.971 & 2.199 & 0.218 \\
\hline
\end{tabular}

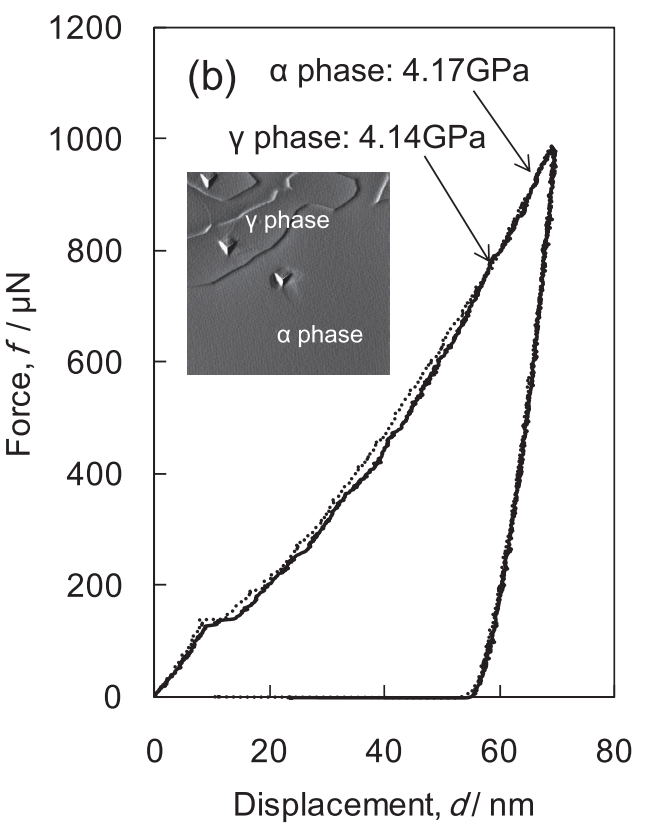

Fig. 15. Image of microstructure and typical load-depth curves for the $\alpha$ and $\gamma$ phases in (a) Type 32101 and (b) Type 329J4L before cold rolling. Straight and dashed lines are for the $\alpha$ and $\gamma$ phase, respectively. 


\section{Conclusions}

In this study, the texture and the planar anisotropy of the $r$-value in the lean DSS Type 32101 cold-rolled and annealed sheet were investigated and the results were compared with those of the standard DSS Type 329J4L sheet. The main results can be summarized as follows:

(1) Type 32101 cold-rolled and annealed sheet had a weaker texture, especially in the $\alpha_{\mathrm{bcc}}$-fiber of the $\alpha$ phase and lower planar anisotropy of the $r$-value than Type 329J4L.

(2) The large difference in texture between Type 32101 and Type 329J4L cold-rolled and annealed sheets was present in the $\alpha_{\mathrm{bcc}}$-fiber and was caused by a decrease in intensity of this fiber during cold rolling in Type 32101.

(3) It was revealed that inhomogeneous deformation easily occurred in Type 32101 because this steel contained a high volume fraction of the $\gamma$ phase, and the difference in hardness between the $\alpha$ and $\gamma$ phases was large in comparison with Type 329J4L.

\section{REFERENCES}

1) J.-O. Nilsson: Mater. Sci. Technol., 8 (1992), 685.

2) J. Charles: Steel Res., 79 (2008), 455.

3) M. Liljas, P. Johansson, H-P. Liu and C-O. A. Olsson: Steel Res., 79 (2008), 466.

4) J. Charles and P. Chemelle: 8th Duplex Stainless Steel Conf., ed. by J. Charles, EDP, Beaune, (2010), 29.

5) P. Johansson and M. Liljas: 4th European Stainless Steel -Sicence and Market Congress, Vol. 2, ATS, Paris, (2002), 153.

6) K. Ichikawa and J. Mclntyre: Stainless Steel World, July/August (2010), 24.

7) C. Herrera, D. Ponge and D. Raabe: Acta Mater., 59 (2011), 4653.

8) N. Tsuchida, T. Kawahata, E. Ishimaru and A. Takahashi: ISIJ Int., 54 (2014), 1971.

9) N. Tsuchida, T. Kawahata, E. Ishimaru, A. Takahashi, H. Suzuki and T. Shobu: ISIJ Int., 53 (2013), 1260.

10) M. Fujisawa, R. Mauchi, T. Morikawa, M. Tanaka and K. Higashida: Tetsu-to-Hagané, 100 (2014), 1140.

11) W. B. Hutchinson, K. Ushioda and G. Runnsjö: Mater. Sci. Technol., 1 (1985), 728.

12) J. J. Moverare and M. Ode'n: Metall. Mater. Trans. A, 33A (2002), 57.

13) G. Fargas, N. Akdut, M. Anglada and A. Mateo: ISIJ Int., 48 (2008),
1596.

14) T. Goto, T. Kondoh, T. Sasaki, Y. Hirose and H. Inoue: Adv. X-ray Anal., 45 (2002), 269.

15) J. Hamada and N. Ono: Mater. Trans., 51 (2010), 635.

16) J. Hamada and H. Inoue: Mater. Trans., 51 (2010), 644.

17) H. Inoue and N. Inakazu: J. Jpn. Inst. Met., 58 (1994), 892.

18) H. Inoue: Materia Jpn., 40 (2001), 589.

19) T. Sawatani, K. Shimizu, T. Nakayama and M. Miyoshi: Tetsu-toHagané, 63 (1977), 843.

20) J. Hamada, N. Ono and H. Inoue: ISIJ Int., 51 (2011), 1740.

21) J. Keichel, J. Foct and G. Gottstein: ISIJ Int., 43 (2003), 1781.

22) J. Keichel, J. Foct and G. Gottstein: ISIJ Int., 43 (2003), 1788.

23) G. I. Taylor: J. Inst. Met., 62 (1938), 307.

24) H. Honneff and H. Mecking: Proc. 5th Int. Conf. on Textures of Materials, ed. by G. Gottstein and K. Lücke, Springer-Verlag, Berlin, (1978), 265.

25) H. Inoue and N. Inakazu: J. Jpn. Inst. Light Met., 44 (1994), 97.

26) H. Inoue: Recrystallization Textures and Their Application to Structure Control, ISIJ, Tokyo, (1999), 174.

27) H. J. Bunge and W. T. Roberts: J. Appl. Cryst., 2 (1969), 116.

28) H. J. Bunge: Texture Analysis in Materials Science, Butterworths, London, (1982), 330.

29) J. Hamada, K. Agata and H. Inoue: Mater Trans., 50 (2009), 752.

30) T. Maki, T. Furuhara and K. Tsuzaki: ISIJ Int., 41 (2001), 571.

31) T. Maki: Netsu Shori, 39 (1999), 5.

32) X. Huang, K. Tsuzaki and T. Maki: Scr. Metall. Mater., 33 (1995), 341.

33) N. Tsuji, K. Tsuzaki and T. Maki: ISIJ Int., 33 (1993), 783.

34) N. Tsuji, K. Tsuzaki and T. Maki: ISIJ Int., 34 (1994), 1008.

35) T. Furuhara, K. Hikita and T. Maki: Mater. Sci. Forum, 304-306 (1999), 53.

36) M. Blicharski: Met. Sci., 18 (1984), 92.

37) F. J. Humphreys and M. Hatherly: Recrystallization and Related Annealing, Pergamon, Oxford, (1995), 401.

38) J. Harase, T. Takeshita and Y. Kawamo: Tetsu-to-Hagané, 77 (1991), 1296.

39) J. Hamada, Y. Matsumoto, F. Fudanoki and S. Maeda: ISIJ Int., 43 (2003), 1989.

40) J. Hamada, S. Maeda, F. Fudanoki, M. Abe, T. Shindo and S. Hashimoto: Tetsu-to-Hagané, 90 (2004), 146.

41) M. Blicharski: Met. Sci., 18 (1984), 99.

42) M. Aramaki, S. Uchida, K. Yasuda, M. Oikawa and O. Furukimi: Tetsu-to-Hagané, 100 (2014), 1261.

43) Y. L. Fang, Z. Y. Liu, W. Y. Xue, H. M. Song and L. Z. Jiang: ISIJ Int., 50 (2010), 286.

44) K. J. Irvine, D. T. Lewllyn and F. B. Pickering: J. Iron Steel Inst., 199 (1961), 153.

45) P. Müllner, C. Solenthaler, P. Uggowitzer and M. O. Speidel: Mater. Sci. Eng., A164 (1993), 164.

46) S. Kubota, Y. Xia and Y. Tomota: ISIJ Int., 38 (1998), 474.

47) T. Tsuchiyama, H. Uchida, K. Kataoka and S. Takaki: ISIJ Int., 42 (2002), 1438. 